\title{
Epidemiological and Clinical Characteristics of Hepatitis C Viral Infections in Tertiary Centres in Sulaimani City / Kurdistan Region of Iraq
}

\author{
Bestun Ibrahim Hama Rahim \\ Community Health Department \\ Sulaimani Technical Institute \\ Sulaimani Polytechnic University \\ Sulaimani, Iraq \\ bestun.rahim@spu.edu.iq
}

\author{
Ali Hattem Hussain \\ Community Health Department \\ Technical College of Health \\ Sulaimani Polytechnic University \\ Sulaimani, Iraq \\ ali.hattem@spu.edu.iq
}

\author{
Mohammed Omer Mohammed \\ Department of Medicine \\ College of Medicine \\ University of Sulaimani \\ Sulaimani, Iraq \\ mohammed.raheem@univsul.edu.iq
}

\begin{abstract}
Hepatitis $C$ infection is one of the most common causes of chronic liver disease. It is growing threat and main burden on public health. Globally more than 170 million people are infected with hepatitis $C$ virus $(\mathrm{HCV})$, up to 4 million new infections annually and each year more than 350000 dies of $\mathrm{HCV}$ related complications, including cirrhosis and hepatocellular carcinoma (HCC). Thus this descriptive case-series study was conducted in five health facilities in Sulaimani city, from 23rd December 2015 to 10th of June 2016. The data were collected from $180 \mathrm{HCV}$ infected patients by face to face interview; they were interviewed privately by using a structured questionnaire. P-values of $\leq 0.05$ were considered statistically significant. Out of 180 patients, $45 \%$ were males and 55\% were females, the mean age of the cases was 33.18 years, regarding marital status $55.5 \%$ of the cases were single. The majority of the cases were diagnosed by routine screening. Most of the patients (70.7\%) had no signs and symptoms at the time of diagnosis. In each patient at least two identifiable risk factors for getting $\mathrm{HCV}$ infection were reported. Among the patients that had genotype test, $67.2 \%$ of them infected with genotyope1. More than threequarters of the participants had elevated alanine aminotransferase (ALT) and aspartate aminotransferase (AST). More future studied parameters and practical skills should be performed to significantly reduce the risk of $\mathrm{HCV}$ infection in Sulaimani.
\end{abstract}

Keywords: hepatitis C epidemiology, risk factors, tertiary centers, Sulaimani.

\section{INTRODUCTION}

$\mathrm{HCV}$ infection is considered a clinical and public health challenge worldwide[1]. The World Health Organization (WHO) estimates that the virus affects roughly $3 \%$ of people worldwide [2]. HCV infects mainly liver cells causing an acute hepatitis, of those acutely infected; approximately $15 \%$ will clear the virus without medical intervention while the rest will develop chronic hepatitis C (CHC). Almost $30 \%$ of $\mathrm{CHC}$ will progress to cirrhosis, of which $20 \%$ will progress HCC [2]. Patients with chronic $\mathrm{HCV}$ are at a great risk of complications from acute hepatitis A virus (HAV) and acute hepatitis B virus (HBV) infections, $\mathrm{HAV}$ and $\mathrm{HBV}$ can be prevented by vaccination and the vaccines have been reported to be safe and effective in individuals infected with chronic HCV [3]. Nosocomial transmission of HCV appears to occur more often in developing countries because best precautions may not be taken. Therapeutic injections by health care workers, shaving by barbers, ear-piercing, tattooing as well as sharing nail clippers, razor blades and toothbrushes known to be associated with HCV infection are commonly encountered in developing countries [4].

Epidemiological information on $\mathrm{HCV}$ is important for strategic prevention of $\mathrm{CHC}$, liver cirrhosis and $\mathrm{HCC}[5]$. There is limited clinical data on $\mathrm{HCV}$ infections in Sulaimani city (Kurdistan Region of Iraq) regarding socio-demography, risk factors for transmission, diagnostic methods, follow up of patients, and control measures. However, there are reported previous studies about HCV prevalence among blood donors, haemodialysis (HD) patients and HCV genotypes in Sulaimani city [6-9].

This study was conducted to identify sociodemographic background, risk factors, clinical presentations and laboratory profiles of HCV patients in Sulaimani city. The study will help health professionals for better planning to control and managing HCV infections in Sulaimani city and will help researchers for suggesting hypothesis for future HCV studies.

\section{PATIENTS AND METHODS}

Patients and study designs

A descriptive case-series study was conducted from $23^{\text {rd }}$ December 2015 to $10^{\text {th }}$ of June 2016 in five health facilities in Sulaimani city which were highly visited by $\mathrm{HCV}$ cases. Convenience sampling method was used for selection of the patients. The current study involved 180 confirmed cases of HCV infections. Eighty of the participants were selected from Kurdistan Centre for Gastroenterology and Hepatology (KCGH), 75 patients were from Sulaimani thalassemia centre of Shahid Hemn Teaching Hospital, fourteen patients were from Sulaimani dialysis centre, seven patients were from 
dialysis centre of Shar Teaching Hospital, and four cases were from Shahid Hadi Consultation Clinic.

The sample size was determined depending on the obtainable time for performing the study and number of HCV infected patients who visited these facilities. Patients with positive anti-HCV antibodies and/or detectable HCV viral load by PCR were regarded as $\mathrm{HCV}$ patients were included in this study except those who co-infected with other hepatitis viruses. The response rate was high $(98.8 \%)$. Constant effort was made to explain the importance of the study and its benefits to the participants and community. Selfadministration questionnaire was used to collect data that included socio-demographic variables, risk factors and clinical data.

Risk factors' score was measured with twelve questions; the patients had two prearranged choices to choose which was (Yes) and (No) answer to conclude risk factors of respondents, each answer with (Yes) worth one mark whereas answer with (No) was given zero. So the total marks were out of twelve.

\section{Statistical analysis}

The Statistical Package for Social Science (SPSS version 22, IBM Statistics.inc) was used for data entry and analysis. Data were entered every day; duplicated data entry was executed to ensure quality control. Two approaches were used: descriptive and analytic. The descriptive approach included the calculation of frequencies, percentages, and means, while in the analytic approach, independent-sample t-test was used to compare between means of two different samples. $\mathrm{P}$-value $\leq 0.05$ was used to show a statistically significant difference. Qualitative and quantitative variables were respectively expressed as percentage and mean \pm 95\% confidence intervals (CI). Texts, Tables and Figures were used for demonstration of the results.

\section{Ethical considerations}

Ethical approval was obtained from both of Sulaimani Polytechnic University and General Directorate of Health in Sulaimani city to performing this study. The patients were recruited for this study informed about the objective of the study and they were free to participate in the study also participation was voluntary. A verbal consent was taken from the patients. The confidentiality of the collected data was guaranteed.

\section{RESULTS}

Overall 180 patients were diagnosed by several techniques of antibody tests, more than half of them $(54.4 \%)$ were diagnosed by enzyme-linked immunosorbent assay (ELISA) test as well as electrochemiluminescence immunoassay (ECLIA) and enzyme linked fluorescent assay (ELFA) were used for diagnosis in $23.9 \%$ and $21.7 \%$ of the cases respectively. Only 149 of them had PCR test.

\section{Socio-demographic characteristics of the HCV patients}

Out of 180 patients, $81(45 \%)$ were males and 99 $(55 \%)$ were females; male-female ratio was $0.82: 1$. The age range of the patients was 6-79 years with mean age was 33.18 (95\% CI 30.68-35.68) years. The mean age of males was 30.21 (95\% CI 26.43-33.99) years; while the mean age of females was 35.61 (95\% CI 32.33-38.89) years. There was a statistically significantly difference between males and females in the mean age $(\mathrm{P}=0.035)$. In our study $93.9 \%$ of the cases were $\geq 15$ years of age and $16.7 \%$ of the patients' age was $\leq 17$ years.

There was a predominant urban distribution of subjects as compared to semi-urban and rural (55\%, $29.4 \%$ and $15.6 \%$ respectively), while more than half of participants $(55.5 \%)$ were single, over one third of them $(36.7 \%)$ were married and only $7.8 \%$ of the patients were widowed. Regarding patients' educational level, the disease was higher in the patients with primary level $(35.6 \%)$ also in the patients with the secondary level was $34.4 \%$ as compare with the other educational levels. In relation to the patients' occupations, the frequency of the disease was higher among students followed by housewife and unemployed $(28.3 \%, 26.7 \%$ and $23.4 \%$ respectively) (Table 1 ).

Table 1: Socio-demographic characteristics of the hepatitis $\mathrm{C}$ patients

\begin{tabular}{|c|c|c|}
\hline Characteristics & Number & Percent \\
\hline \multicolumn{3}{|l|}{ Gender } \\
\hline Male & 81 & 45.0 \\
\hline Female & 99 & 55.0 \\
\hline \multicolumn{3}{|l|}{ Age (years) } \\
\hline$\leq 14$ & 11 & 6.1 \\
\hline $15-29$ & 82 & 45.5 \\
\hline $30-44$ & 41 & 22.8 \\
\hline $45-59$ & 23 & 12.8 \\
\hline$\geq 60$ & 23 & 12.8 \\
\hline \multicolumn{3}{|l|}{ Residence } \\
\hline Urban & 99 & 55.0 \\
\hline Semi-urban & 53 & 29.4 \\
\hline Rural & 28 & 15.6 \\
\hline \multicolumn{3}{|l|}{ Marital status } \\
\hline Married & 66 & 36.7 \\
\hline Widowed & 14 & 7.8 \\
\hline Single & 100 & 55.5 \\
\hline \multicolumn{3}{|l|}{ Education } \\
\hline Illiterate & 34 & 18.9 \\
\hline Primary & 64 & 35.6 \\
\hline Secondary & 62 & 34.4 \\
\hline High education & 20 & 11.1 \\
\hline \multicolumn{3}{|l|}{ Occupation } \\
\hline Government employee & 19 & 10.5 \\
\hline Self-employed & 20 & 11.1 \\
\hline Students & 51 & 28.3 \\
\hline Housewife & 48 & 26.7 \\
\hline Unemployed & 42 & 23.4 \\
\hline Total & 180 & 100.0 \\
\hline
\end{tabular}

\section{Patients' status at the time of diagnosis}

At the time of diagnosis majority of the patients 127 (70.7\%) had no signs and symptoms of the disease, only $53(29.3 \%)$ of them had them such as jaundice, arthralgia, dark urine, abdominal pain and hepatomegaly and clay coloured stool (Table 2). 
Table 2: Distribution of hepatitis $\mathrm{C}$ by the signs and symptoms

\begin{tabular}{ccc}
\hline Signs and symptoms & Number & Percent \\
\hline Jaundice & 35 & 19.4 \\
Yes & 145 & 80.6 \\
No & 33 & 18.3 \\
Arthralgia & 147 & 81.7 \\
Yes & & \\
No & 24 & 13.3 \\
Dark urine & 156 & 86.7 \\
Yes & & \\
No & 21 & 11.7 \\
Abdominal pain & 159 & 88.3 \\
Yes & & \\
No & 19 & 10.6 \\
Hepatomegaly & 161 & 89.4 \\
Yes & & \\
No & 16 & 8.9 \\
Clay coloured stool & 164 & 91.1 \\
Yes & $\mathbf{1 8 0}$ & $\mathbf{1 0 0 . 0}$ \\
No & & \\
Total & &
\end{tabular}

Distribution of the hepatitis $\mathrm{C}$ patients by certain risk factors

Table 3: Distribution of the hepatitis $\mathrm{C}$ patients by certain risk factors

\begin{tabular}{|c|c|c|}
\hline History of risk factors & Number & Percent \\
\hline \multicolumn{3}{|l|}{ Disease in the family } \\
\hline Yes & 24 & 13.3 \\
\hline No & 156 & 86.7 \\
\hline \multicolumn{3}{|l|}{ Blood transfusion } \\
\hline Yes & 137 & 76.1 \\
\hline No & 43 & 23.9 \\
\hline \multicolumn{3}{|l|}{ Organ transplantation } \\
\hline Yes & 6 & 3.3 \\
\hline No & 174 & 96.7 \\
\hline \multicolumn{3}{|l|}{ Dental procedures } \\
\hline Yes & 106 & 58.9 \\
\hline No & 74 & 41.1 \\
\hline \multicolumn{3}{|l|}{ Surgical procedures } \\
\hline Yes & 126 & 70.0 \\
\hline No & 54 & 30.0 \\
\hline \multicolumn{3}{|l|}{ Cupping (Hijama) } \\
\hline Yes & 23 & 12.8 \\
\hline No & 157 & 87.2 \\
\hline \multicolumn{3}{|l|}{ Tattooing } \\
\hline Yes & 23 & 12.8 \\
\hline No & 157 & 87.2 \\
\hline \multicolumn{3}{|c|}{ Piercing body other than ear } \\
\hline Yes & 9 & 5.0 \\
\hline No & 171 & 95.0 \\
\hline \multicolumn{3}{|l|}{$\begin{array}{l}\text { Repeated therapeutic drug } \\
\text { injection }\end{array}$} \\
\hline Yes & 111 & 61.7 \\
\hline No & 69 & 38.3 \\
\hline \multicolumn{3}{|c|}{ Sharing sharp medical objects } \\
\hline Yes & 8 & 4.4 \\
\hline No & 172 & 95.6 \\
\hline \multicolumn{3}{|c|}{ Sharing personal hygiene items } \\
\hline Yes & 147 & 81.7 \\
\hline No & 33 & 18.3 \\
\hline \multicolumn{3}{|l|}{ Traveling abroad } \\
\hline Yes & 49 & 27.2 \\
\hline No & 131 & 72.8 \\
\hline Total & 180 & 100.0 \\
\hline
\end{tabular}

\section{Risk factors score of the patients regarding} hepatitis $\mathbf{C}$

The risk factors score ranged from 2 to 9 , the mean score of the patients regarding risk factors of the disease was 4.47 (95\% CI 4.25-4.70) (Figure 1).

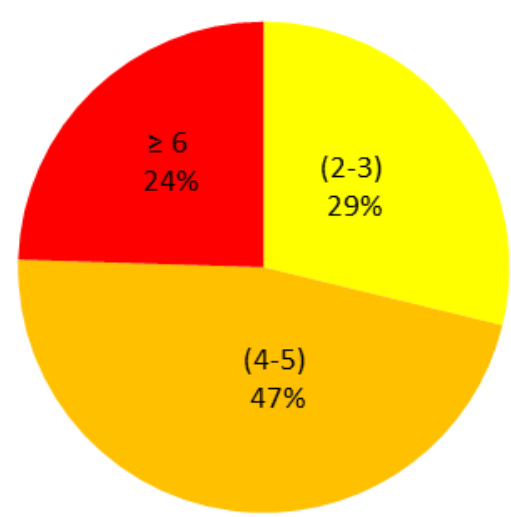

Figure 1 Relative frequencies of risk factors score of the patients regarding hepatitis $\mathrm{C}$

\section{Hepatitis $\mathrm{C}$ in relation to high risk groups and non- high risk group}

The study sample included high risk groups to $\mathrm{HCV}$ infection which were thalassemic patients (48.3\%), HD patients $(21.7 \%)$, diabetes mellitus (DM) patients $(12.2 \%)$ and hemophilic patients $(3.9 \%)$, whereas non high risk group constituted $13.9 \%$ (Figure 2).

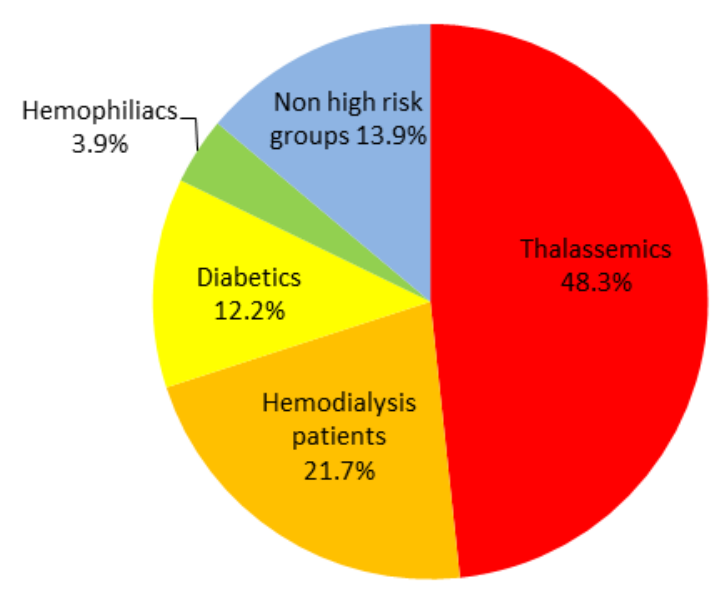

Figure 2 Distribution of HCV by high risk groups and nonhigh risk group 
Vaccinations against hepatitis $A$ and hepatitis B viruses

Out of 180 patients, only $46.1 \%$ of the patients received $\mathrm{HBV}$ and none of them received $\mathrm{HAV}$ (Figure 3).

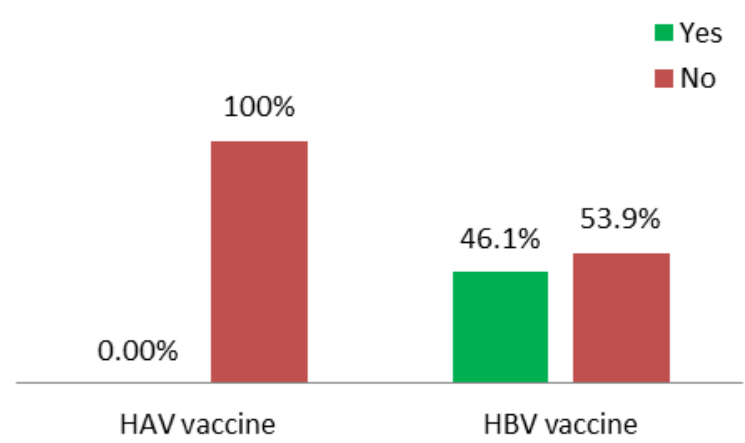

Figure 3 Vaccinations against hepatitis A and hepatitis B viruses

\section{Laboratory tests}

The main reasons for performing anti-HCV antibody tests

Table 4: The main reasons for performing anti-HCV antibody tests

\begin{tabular}{|c|c|c|}
\hline Reasons & Number & Percent \\
\hline $\begin{array}{l}\text { Screening of asymptomatic } \\
\text { patient reported with high risk } \\
\text { groups }\end{array}$ & 77 & 42.8 \\
\hline $\begin{array}{l}\text { Assessing of symptomatic } \\
\text { patient reported with high risk } \\
\text { groups }\end{array}$ & 24 & 13.3 \\
\hline Pre-surgical screening & 25 & 13.9 \\
\hline Pre-dental procedure screening & 16 & 8.9 \\
\hline Symptoms of hepatitis C & 15 & 8.3 \\
\hline Other reasons & 23 & 12.8 \\
\hline Total & 180 & 100.0 \\
\hline
\end{tabular}

\section{Frequency of HCV genotypes}

A total 58 patients had undergone HCV genotyping test as displayed in Table 5.

Table 5: Distribution of HCV genotypes among the

\begin{tabular}{|c|c|c|}
\hline Genotype & Number & Percent \\
\hline 1 & 39 & 67.2 \\
\hline $1 \mathrm{a}$ & 24 & 41.3 \\
\hline $1 b$ & 15 & 25.9 \\
\hline 2 & 2 & 3.5 \\
\hline 3 & 1 & 1.7 \\
\hline 4 & 16 & 27.6 \\
\hline Total & 58 & 100.0 \\
\hline
\end{tabular}

\section{Liver enzymes tests (ALT, AST)}

Over all, the result demonstrated that 166 out of 180 patients had ALT and AST tests, consisted of 74 males and 92 females. In general $25.9 \%$ of the patients had normal ALT level and $74.1 \%$ of them had elevated ALT level while $21.1 \%$ of the patients had normal AST level and $78.9 \%$ of them had elevated AST level.
ALT concentration elevation was higher in females compared to males ( $81.5 \%$ and $64.9 \%$ respectively); likewise AST concentration elevation was higher in females compared to males $(85.9 \%$ and $70.3 \%$ respectively) (Table 6).

Table 6: Liver enzymes (ALT, AST) tests regarding gender

\begin{tabular}{ccc}
\multicolumn{3}{c}{ regarding gender } \\
\hline ALT & & \\
Male & Number & Percent \\
$>30 \mathrm{U} / \mathrm{L}$ & 48 & 64.9 \\
$\leq 30 \mathrm{U} / \mathrm{L}$ & 26 & 35.1 \\
Total & $\mathbf{7 4}$ & $\mathbf{1 0 0 . 0}$ \\
& & \\
Female & & \\
$>19 \mathrm{U} / \mathrm{L}$ & 75 & 81.5 \\
$\leq 19 \mathrm{U} / \mathrm{L}$ & 17 & 18.5 \\
Total & $\mathbf{9 2}$ & $\mathbf{1 0 0 . 0}$ \\
AST & & \\
& & \\
Male & Number & Percent \\
$>30 \mathrm{U} / \mathrm{L}$ & 52 & 70.3 \\
$\leq 30 \mathrm{U} / \mathrm{L}$ & 22 & 29.7 \\
Total & $\mathbf{7 4}$ & $\mathbf{1 0 0 . 0}$ \\
& & \\
Female & & 85.9 \\
$>19 \mathrm{U} / \mathrm{L}$ & 79 & 14.1 \\
$\leq 19 \mathrm{U} / \mathrm{L}$ & 13 & $\mathbf{1 0 0 . 0}$ \\
Total & $\mathbf{9 2}$ &
\end{tabular}

\section{AST: ALT ratio}

The Figure showed that $86(52 \%)$ of the patients had AST: ALT ratio > 1 and $80(48 \%)$ of the patients had AST: ALT ratio $\leq 1$.

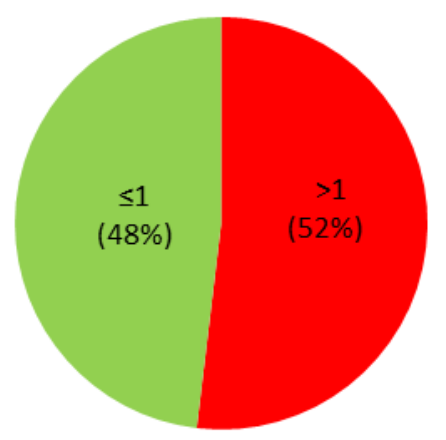

Figure 4 Relative frequencies of AST: ALT ratios

\section{DISCUSSION}

\section{Socio-demographic characteristics of the hepatitis C} patients

The current study found that $55 \%$ of the patients were females and $45 \%$ were males. A study in Mashhad (Iran) affirmed that the association between the HCV antibody positivity and gender was not statistically significant [10]; the female predominance in gender in our study sample could be explained from the fact that females are more prone to the risk factors for this infection such as cosmetic surgery.

In the present study, the females were found to be obviously older compared to males (mean age, $35.61 \mathrm{vs}$ 
30.21, $\mathrm{P}=0.035)$, this significant finding was showed in other case series study which was carried out in northeastern Poland [11]. Moreover, a cross-sectional survey was conducted in the Republic of Ireland indicated that females were significantly older than males [12]. The differences in mean age of males and females among our patients could be explained by the fact that rate of chronicity in HCV infection seems to be lower in women, especially younger women [13].

In our study $93.9 \%$ of the cases were $\geq 15$ years of age. A study observed that annual incidence of seropositivity in those age $\geq 15$ years were nearly 45 fold higher than children $<15$ years of age [14].

In the present study, majority of the patients $(55 \%)$ were from urban areas, this finding is similar to the study was done in north-eastern Poland [11]. Conversely, a study was conducts in Alexandria (Egypt) found that most of the patients were from rural setting [15]. This high distribution among urban patients in our study may be partially due to the fact that study was conducted in health facilities that located in the city centre, also the ratio of urban/rural population are more and the risks of $\mathrm{HCV}$ transmission are more common among urban than rural.

In the current study, the frequency of $\mathrm{HCV}$ infection was high $(55.5 \%)$ among single patients. Likewise, a cross-sectional study found the significant association between positive results for hepatitis $\mathrm{C}$ and marital status; single, widowed and divorced individuals have a greater chance of having $\mathrm{HCV}$ than married individuals [16]. On the contrary, another survey reported that the association between $\mathrm{HCV}$ infection and marital status was not statistically significant [17]. The differences in marital status among our patients could be explained by almost half of the study sample participants were thalassemics that have difficulty in marriage process, and $16.7 \%$ of the patients' age was $\leq 17$ years, those were under age of marriage.

The study found that the disease was higher in the primary and secondary levels (35.6\% and 34.4\%) respectively than other educational levels. Conversely, a study was conducted in Nigeria in 2014 reported that the $\mathrm{HCV}$ infection was not significantly associated with educational levels [18].

Regarding patients' occupations; the students occupied the first place $(28.3 \%)$ this refers to that students behave less attentively regarding some facts that affect their lives and health. However a study carried out in Serbia in which the disease was high in unemployed patients [19].

\section{Patients' status at the time of diagnosis}

Only $29.3 \%$ of the subjects were symptomatic at the time of diagnosis. Our finding is in agreement with a systematic review study was conducted in Egypt, showed that $25-30 \%$ of patients with acute HCV infection develop symptoms [20]. Another study was conducted on 77 Italian and Spanish children, observed that $\mathrm{HCV}$ was commonly asymptomatic among them [21].

\section{Risk factors scores of patients regarding hepatitis C}

Risk factors for HCV transmission were found in all study patients. In each patient at least two identifiable risk factors for acquiring $\mathrm{HCV}$ were reported. Likewise another study was conducted in Egypt found each patient had at least three risk factors for getting $\mathrm{HCV}$ [15]. Our findings are inconsistent with the findings of a study revealed that in $20 \%$ of patients the agent transmission happened by unknown route [22].

\section{Vaccinations against HAV and HBV}

A noticeable finding in this study was none of the patients received hepatitis A vaccine and only $46.1 \%$ of them received hepatitis B. In contrast, a cohort study was conducted on $\mathrm{CHC}$ patients in USA reported that $56.3 \%$ of them were vaccinated against hepatitis $\mathrm{A}$ and $59.1 \%$ of them were vaccinated against hepatitis B [23]. Our result may be due to hepatitis A vaccine is not available in adequate number till meet needs of the risk groups; in addition in our country majority people got HAV infection in childhood which provided immunity to them. However, hepatitis B vaccine is available in our country, but more than half of the cases not received the vaccine this is might be due to they have no sufficient information about importance of receiving hepatitis $\mathrm{B}$ vaccine.

\section{The main reasons for performing anti-HCV antibody test}

Majority of the cases including in our study were detected on screening, without having any signs and symptoms of the disease. Our findings are in agreement with findings of a study was conducted in India in 2010 reported that the high proportion of $\mathrm{HCV}$ cases was incidentally identified on routine screening [24]. This could be explained from the fact that majority of $\mathrm{HCV}$ cases are asymptomatic [25], therefore most of the infected individuals were not aware of their infection and majority of them were diagnosed by routine screening.

\section{Frequency of HCV genotypes}

The current study observed that among the patients who had genotype test, genotype 1 had been highly prevalent followed by genotype $4(67.2 \%$ and $27.6 \%$ respectively). Globally, genotype 1 is estimated to account for more HCV cases than any other genotypes, while Middle East has a large number of genotype 4 [26]. On the other hand, genotype 4 is the cause of about $20 \%$ of the 170 million cases of HCV in the world [21]. Our finding regarding genotype 1 is nearly consistent with the result of a study was conducted in Sulaimani city in 2009 that revealed $87 \%$ of study patients had genotype 1 [9].

\section{Liver transferase (ALT and AST)}

The current study found that $25.9 \%$ of the patients had normal ALT. In contrast a study was conduct in north Italy reported $67.62 \%$ of the patients had normal ALT [27]. Our result may be due to the patients had no commitment with the prescriptive antiviral drugs. In the present study $78.9 \%$ of the patients had elevated AST this figure is inconsistent with a study was conducted in New Delhi [28]. Moreover, a survey was performed in 
urban areas of Antananarivo-Madagascar found high aminotransferase ALT and AST activity was significantly associated with anti-HCV positivity, and patients with active HCV infection [17].

\section{AST: ALT ratio}

The result indicated that more than half $(51.9 \%)$ of the patients had AST: ALT ratio greater than one and this represent an undesired laboratory result for these patients. The ratio is usually less than one in viral hepatitis, the ratio always rises to more than one as cirrhosis develops perhaps because of reduced plasma clearance of AST secondary to decreased function of sinusoidal cells, ALT exceeds AST in viral hepatitis, chronic active hepatitis, toxic hepatitis, and cholestatic hepatitis [29].

\section{Strengths and limitations of the study}

The strength of this study lies in that the study population selected from multi-health facilities, where were highly visited by $\mathrm{HCV}$ patients for receiving various services and treatments. Up to our knowledge, this is the first study in Kurdistan region that assessed the patients for history of receiving hepatitis A and hepatitis B vaccines.

However, face to face interview has great advantage in collecting data, but also has some negative impacts in disclosing some personal information which are sensitive and private risk factors regards as taboo and social stigmatic issues such as sexual promiscuity and drug abuse, these together not included in this study could influence the results. During pilot study, some young males were asked about extra marital sexual relationship and substance abuse some of them denied and others refused to answer the questions rigorously. The viral genotype and viral load were not done for all patients because they were not available in governmental laboratories and they were expensive in private laboratories.

\section{COCLUSIONS}

This study showed that most of HCV patients were asymptomatic at the time of diagnosis. High proportion of the cases was diagnosed on routine screening. Majority of HCV infected patients had history of sharing personal hygiene items, blood transfusion and therapeutic drug injection. The disease was more common among high risk groups. Over half of the patients were not received HBV vaccine and none of them received HAV vaccine. The most common genotypes among the patients were genotypes 1 and 4 . Majority of the cases had elevated liver enzymes (ALT, AST).

\section{REFERENCES:}

[1] C. Treloar, J. Rance, and M. Backmund, "Understanding Barriers to Hepatitis C Virus Care and Stigmatization From a Social Perspective," Clinical Infectious Diseases, vol. 57, pp. S51-S55, 2013.

[2] K. L. MacArthur, C. H. Wu, and G. Y. Wu, "Animal models for the study of hepatitis C virus infection and replication," World $J$ Gastroenterol, vol. 18, pp. 2909-13, 2012.

[3] M. D. Howard K. Koh, M.P.H and Ronald O. Valdiserri, M.D., M.P.H., "Action Plan for the Prevention, Care, \& Treatment of Viral Hepatitis 2014-2016," 2014.

[4] A. Bari, S. Akhtar, M. H. Rahbar, and S. P. Luby, "Risk factors for hepatitis C virus infection in male adults in RawalpindiIslamabad, Pakistan," Tropical Medicine \& International Health, vol. 6, pp. 732-738, 2001.

[5] E. Hajiani, R. Masjedizadeh, J. Hashemi, M. Azmi, and T. Rajabi, "Hepatitis $\mathrm{C}$ virus transmission and its risk factors within families of patients infected with hepatitis $\mathrm{C}$ virus in southern Iran: Khuzestan," WJG, vol. 12, pp. 7025-7028, 2006.

[6] Z. S. Ramzi, A. A. Abdulla, T. AL-Hadithi, and N. Al-Tawil, "Prevalence and Risk Factors for Hepatitis C Virus Infection in Hemodialysis Pateints in Sulaimani," Zanco J. Med. Sci., vol. 14, pp. 44-50, 2010.

[7] M. O. MOHAMMED, "Prevalence of Hepatitis$\mathrm{B}$ and Hepatitis-C among blood donors in Sulaimani city," JZS, vol. Part A, 9, pp. 1-7, 2006.

[8] A. H. Hussein, "Seroprevalence of Hepatitis B and C Viruses among Blood Donors in Sulaimani Major Blood Bank for the Years 2006 and 2007: A Comparative Study," Journal of Zankoy Sulaimani, vol. 13, pp. 15-20, 2010.

[9] B. O., Kareem, and G. F. Salih, "HEPATITIS C VIRUS GENOTYPING IN SULAIMANI GOVERNORATE," European Scientific Journal, vol. 10, pp. 1857 - 7881, 2014.

[10] M. T. Shakeri, H. Nomani, M. G. Mobarhan, H. Reza, Sima, S. Gerayli, et al., "The Prevalence of Hepatitis C Virus in Mashhad, Iran: A Population-Based Study," Hepat Mon. , vol. 13, pp. 2-5, 2013.

[11] S. Chlabicz, R. Flisiak, A. Grzeszczuk, O. Kovalchuk, D. Prokopowicz, and L. Chyczewski, "Known and probable risk factors for hepatitis $\mathrm{C}$ infection: A case series in northeastern Poland," WJG, vol. 12, pp. 141-145, 2006.

[12] O. McKenna, C. Cunningham, and C. Blake, "Socio-demographic and clinical features of Irish iatrogenic hepatitis $\mathrm{C}$ patients: a crosssectional survey," BMC Public Health, vol. 9, pp. 1-11, 2009.

[13] S. L. Chen and T. R. Morgan, "The Natural History of Hepatitis C Virus (HCV) Infection," nt. J. Med. Sci, vol. 3, pp. 47-52, 2006.

[14] A. S. Alghamdi, F. M. Sanai, M. Ismail, H. Alghamdi, K. Alswat, A. Alqutub, et al., "SASLT Practice Guidelines: Management of Hepatitis C Virus Infection," Saudi Journal of Gastroenterology : Official Journal of the Saudi Gastroenterology Association, vol. 18, pp. S1S32, 2012.

[15] E. W. Abd El-Wahab, A. Mikheal, F. Sidkey, and H. Z. Shatat, "Factors Associated with Hepatitis C Infection among Chronic HCV 
Egyptian Patients," Iranian Journal of Public Health, vol. 43, pp. 1510-1518, 2014.

[16] J. R. Neto, M. R. Cubas, S. Z. Kusma, and M. Olandoski, "Prevalence of hepatitis $\mathrm{C}$ in adult users of the public health service of São José dos Pinhais - Paraná," Rev Bras Epidemiology vol. 15, pp. 627-38, 2012.

[17] C. E. Ramarokoto, F. Rakotomanana, M. Ratsitorahina, V. Raharimanga, R. Razafindratsimandresy, R. Randremanana, et al., "Seroprevalence of hepatitis $\mathrm{C}$ and associated risk factors in urban areas of Antananarivo, Madagascar," BMC Infect Dis, vol. 8, pp. 1-7, 2008.

[18] C. A. Onyekwere, A. O Ogbera, A. Olusola Dada, O. O Adeleye, A. O Dosunmu, A. A. Akinbami, et al., "Hepatitis C Virus (HCV) Prevalence in Special Populations and Associated Risk Factors: A Report From a Tertiary Hospital," Hepat Mon, vol. 16, pp. 1-5, 2016.

[19] M. Kostić, B. Kocić, and L. P. Dragonjić., "Epidemiological Characteristics of Carriers of Antibody Against Hepatitis C Virus in the Population of Nišava District," ACTA FACULTATIS MEDICAE NAISSENSIS, vol. 31, pp. 51-58, 2014.

[20] S. M. Kamal, "Acute Hepatitis C: A Systematic Review," Am J Gastroenterol, vol. 103, pp. 1283-1297, 2008.

[21] F. Nouroz, S. Shaheen, G. Mujtaba, and S. Noreen, "An overview on hepatitis C virus genotypes and its control," Egyptian Journal of Medical Human Genetics, vol. 16, pp. 291-298, 2015.

[22] d. A. R. A. Pondé, "Hidden hazards of HCV transmission," Medical Microbiology and Immunology, vol. 200, pp. 7-11, 2011.
[23] E. Henkle, M. Lu, L. B. Rupp, J. A. Boscarino, V. Vijayadeva, M. A. Schmidt, et al., "Hepatitis $\mathrm{A}$ and $\mathrm{B}$ Immunity and Vaccination in Chronic Hepatitis B and C Patients in a Large United States Cohort," Clinical Infectious Diseases, vol. 60, pp. 514-522, 2015.

[24] P. Singh, R. Kaur, and A. Kaur, "Frequency distribution of Hepatitis $\mathrm{C}$ virus in different geographical regions of Punjab: Retrospective study from a tertiary care centre in North India," Journal of Natural Science, Biology, and Medicine, vol. 5, pp. 56-58, 2014.

[25] E. Gupta, M. Bajpai, and A. Choudhary, "Hepatitis C virus: Screening, diagnosis, and interpretation of laboratory assays," Asian Journal of Transfusion Science, vol. 8, pp. 1925, 2014.

[26] J. P. Messina, I. Humphreys, A. Flaxman, A. Brown, G. S. Cooke, O. G. Pybus, et al., "Global Distribution and Prevalence of Hepatitis C Virus Genotypes," HEPATOLOGY, vol. 61, pp. 77-87, 2015.

[27] C. Mazzeo, F. Azzaroli, S. Giovanelli, A. Dormi, D. Festi, A. Colecchia, et al., "Ten year incidence of $\mathrm{HCV}$ infection in northern Italy and frequency of spontaneous viral clearance," Gut vol. 52, pp. 1030-1034, 2003.

[28] H. S. Rehan, D. Chopra, M. Yadav, N. Wardhan, S. Manak, K. M. Siddiqui, et al., "Safety and efficacy of Qurse-e-istisqua in chronic hepatitis C Infection: An exploratory study," Indian Journal of Pharmacology, vol. 47, pp. 72-79, 2015.

[29] B. R. Thapa and A. Walia, "Liver Function Tests and their Interpretation," Indian Journal of Pediatrics, vol. 74, 2007. 